Georgios Dimitropoulos

\title{
Zertifizierung und Akkreditierung im Internationalen Verwaltungsverbund
}

\author{
Internationale Verbundverwaltung und gesellschaftliche Administration
}

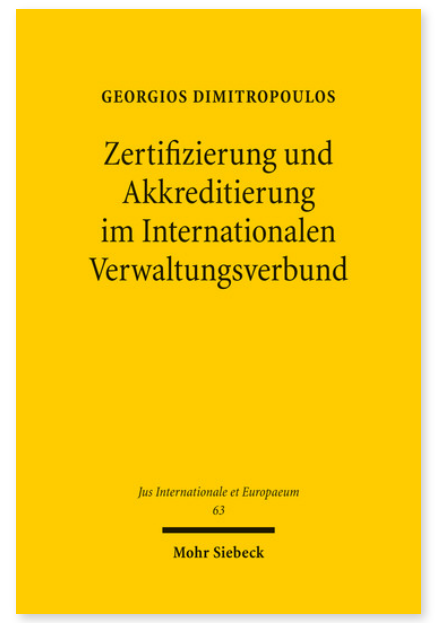

2012. XXIV, 418 Seiten. JusIntEu 63

ISBN 978-3-16-151939-0

DOI 10.1628/978-3-16-151939-0

eBook PDF 94,00€

ISBN 978-3-16-150988-9

fadengeheftete Broschur 94,00€
Moderne Verwaltung entwickelt neue Instrumente für den Umgang mit Bürgern und Unternehmen sowie mit ausländischen und supranationalen Verwaltungen. Repräsentativ für diese Veränderung ist das System der Zertifizierung und Akkreditierung. Dieses System hat sich auf dem privaten Markt entwickelt. Seit einiger Zeit wird es zunehmend auch zur Erfüllung administrativer Ziele eingesetzt. Dazu wird seine Verbreitung von der globalen und europäischen Verwaltungsebene vorangetrieben. In den Referenzgebieten Konformitätsbewertung, Produktsicherheit, Nachhaltigkeit und Klimaschutz zeigen sich auch neue Formen internationaler Verwaltung. Es entsteht ein Internationaler Verwaltungsverbund. Dieser dient als das funktionale Äquivalent zum Staat für das Verwalten jenseits des Staates. Neue administrative Phänomene treten in diesem Rahmen zutage: dekonzentrierte internationale Implementation, Verbundverwaltung und gesellschaftliche Administration. Der Verbund wird durch ein internationales Kooperationsprinzip und ein internationales rule of law- Prinzip normativ verfestigt.

Georgios Dimitropoulos Geboren 1984; Studium der Rechtswissenschaft in Athen und Heidelberg; 2011 Promotion inHeidelberg; seit 2011 Global Research Fellow an der School of Law der New York University, New York, USA.

Jetzt bestellen:

https://mohrsiebeck.com/buch/zertifizierung-und-akkreditierung-im-internationalen-verwaltungsverbund-9783161519390? no_cache=1

order@mohrsiebeck.com

Telefon: +49 (0)7071-923-17

Telefax: $+49(0) 7071-51104$ 